\title{
Contribuições epistemológicas da abordagem multirreferencial para a compreensão dos fenômenos educacionais
}

\author{
João Batista Martins
}

Universidade Estadual de Londrina, Departamento de Psicologia Social e Institucional

\begin{abstract}
Pusemo-nos a destrinchar o processo da vida com nossas tesouras de pesquisa. Fomos do organismo para o órgão, do órgão ao tecido, do tecido à célula, até chegarmos à molécula de DNA em seu ambiente celular. Continuamos a picotar. Decompusemos o DNA. Decompusemos o ambiente. Com surpresa, descobrimos que a vida desapareceu. Para onde ela foi?
\end{abstract}

Schwartz, 1992

\section{Introdução}

Pretendemos trazer para discussão algumas contribuições da abordagem multirreferencial desenvolvida por Jacques Ardoino para a compreensão dos fenômenos sociais e, mais especificamente, aqueles que se circunscrevem no âmbito da educação, enfocando especificamente alguns desdobramentos epistemológicos.

Esta abordagem, à medida que pretende assegurar a complexidade de tais fenômenos, pressupõe a conjugação de uma série de abordagens, disciplinas etc. de tal forma que elas não se reduzam umas às outras e nos levem a um tipo de conhecimento que se diferencia daquele que é concebido na ótica do cartesianismo e do positivismo, caracterizando-se, principalmente, pela pluralidade e heterogeneidade.

Nesse sentido, a abordagem multirreferencial pode ser considerada como uma (entre várias) resposta às críticas que são dirigidas aos modelos científicos estruturados a partir do racionalismo cartesiano e do positivismo comteano. Japiassu (1975) assinala que quando as ciências humanas se instauraram elas buscaram seu reconhecimento e sua legitimidade como ciências apoiando-se em paradigmas então consagrados pelas ciências naturais. Objetividade e neutralidade são almejadas em direção a um conhecimento positivo da realidade humana. Buscar nas ciências naturais os meios para garantir a legitimidade científica fez com que as ciências humanas assumissem os pressupostos das ciências naturais, incorporando uma perspectiva epistemológica e, em consequiência, uma perspectiva metodológica que não lhe é própria, o que não nos possibilita explicitar os fenômenos humanos em sua profundidade - em sua complexidade. 
A perspectiva epistemológica positivista é marcada pela visão elementarista e determinista sobre a realidade, próprias à física newtoniana, na qual a metáfora utilizada para descrever o universo, como uma máquina perfeita, é marcada pelo pensamento cartesiano (Capra, 1982). Certamente, a concepção de uma realidade absoluta, supra-histórica, governada por leis imutáveis, apresenta uma longa história no pensamento ocidental. Ela remonta à antiguidade grega, em que a concepção de uma realidade estável, fixa, na qual a mudança é uma ilusão (pensamento filosófico présocrático de Parmênides), se opunha à concepção de uma realidade fluída, processual, na qual o estável é uma ilusão (idéia defendida por Heráclito de Éfeso, considerado o "pai" do pensamento dialético).

No decorrer da história do pensamento filosófico ocidental, a noção de uma realidade imutável, externa ao sujeito do conhecimento, tornou-se dominante. Nesse sentido, nos séculos XVII e XVIII, as duas perspectivas epistemológicas majoritárias, o racionalismo e o empirismo, apesar de todas as suas divergências, compartilhavam duas premissas básicas: separação radical entre o sujeito e o objeto do conhecimento; e uma relação linear e isomórfica do conhecimento com a realidade (González Rey, 1997).

Tais premissas são retomadas e radicalizadas, no século XIX, pela perspectiva positivista que se torna a referência epistemológica dominante nas ciências modernas. Em linhas gerais, o positivismo apresenta as seguintes características (idem):

- separação excludente entre sujeito (pesquisador) e objeto de estudo;

- a subjetividade e a afetividade são consideradas de forma pejorativa, como fonte de erro;

- supervalorização do método e desprezo pela teoria e interpretação: visão instrumentalista do conhecimento;

- crença no empreendimento científico como algo neutro, objetivo;

- o método científico é considerado de forma monolítica (o que varia são os objetos de estu- do, o método de investigação é o mesmo para todas as ciências);

- os objetivos da ciência seriam a descrição imparcial, a predição e o controle sobre a realidade.

Coerente com a premissa da separação exclusiva entre sujeito e objeto do conhecimento, a perspectiva epistemológica positivista assume uma conotação legalista (Prigogine, 1996): a natureza segue leis simples, imutáveis; cabendo aos cientistas a descrição de tais leis, com base em métodos validados cientificamente.

Dentro dessa lógica, a complexidade, os processos fluídos são meras ilusões; a realidade seria ordenada por leis simples que regem os fenômenos físicos, biológicos e sociais, cuja descrição fidedigna pressupõe a adoção de instrumentos válidos, prescindindo do sujeito do conhecimento, bem como do contexto cultural em que se insere a atividade de pesquisa. A tentativa de eliminação tanto da dimensão contextual como subjetiva acaba por fortalecer o mito da neutralidade científica e do controle dos pesquisadores em relação aos fenômenos estudados (Japiassu, 1975).

A perspectiva multirreferencial propõe, por sua vez, abordar as questões anteriores tendo como objetivo estabelecer um novo "olhar" sobre o "humano", mais plural, a partir da conjugação de várias correntes teóricas, o que se desdobra em nova perspectiva epistemológica na construção do conhecimento sobre os fenômenos sociais, principalmente os educativos.

\section{A emergência da noção de multirreferencialidade}

A noção, ou melhor, a abordagem multirreferencial, foi esboçada inicialmente por Jacques Ardoino, professor da Universidade de Vincennes (Paris VIII), e seu grupo de trabalho. Em vários momentos de sua obra, Ardoino assinala que o aparecimento da idéia da abordagem multirreferencial no âmbito das ciências humanas, e especialmente da educação, está di- 
retamente relacionada com o reconhecimento da complexidade e da heterogeneidade que caracterizam as práticas sociais. Segundo ele "Foi efetivamente, em 1966, especialmente em Communications et Relations Humaines [...], no prefácio a La pedagogie institutionnelle, de Michel Lobrot [...], e na revista Education Nationale [...], de junho de 1967, que foram delineadas as primeiras noções deste procedimento a respeito das situações educativas representadas como complexas" (Ardoino apud Barbosa, 1998, p. 200).

Em seus trabalhos iniciais, o referido autor estabelece o que denominou de modelo de inteligibilidade das organizações; suas preocupações o aproximam de outros intelectuais vinculados ao que é conhecido como Movimento de Análise Institucional. Para ele, a análise institucional é uma forma de introdução para a análise multirreferencial (Ardoino, 1998a), visto que ambas têm o mesmo objetivo, qual seja, permitir uma certa explicação - uma elucidação - do não-dito, das entrelinhas, do movimento latente, implícito nas práticas sociais, entre elas a educação (Ardoino, 1995a). A análise multirreferencial, por sua vez, caracterizase como um modelo de inteligibilidade específico, que veio a se tornar conhecido por "análise institucional multirreferencial, ou plural" (Ardoino, 1998b, p. 43).

Cabe salientar que Ardoino, numa das citações precedentes, denomina a abordagem multirreferencial de procedimento, referindo-se ao modelo de inteligibilidade esboçado em 1966. Nesse sentido, podemos dizer que essa abordagem é, inicialmente, uma resposta ao caráter extremamente complexo da prática social e, principalmente, das práticas educativas. Tal complexidade traz para aqueles que estão envolvidos com questões educacionais (professores, pedagogos, psicólogos etc.) uma série de dificuldades de leitura e de compreensão sobre suas próprias práticas, o que se desdobra em dificuldades de tomar decisões (Ardoino, 1998c).

$\mathrm{Se}$, num primeiro momento, a abordagem multirreferencial se caracteriza como um procedimento, notamos, ao longo dos trabalhos de Ardoino, que suas preocupações se voltaram para as questões epistemológicas implícitas no procedimento proposto.
Sua postura epistemológica se estrutura com base no reconhecimento do caráter plural dos fenômenos sociais:

\section{[...] quer dizer que no lugar de buscar um sistema explicativo unitário [...] as ciências humanas necessitam de explica- ções, ou de olhares, ou de óticas, de perspectivas plurais para dar conta um pouco melhor, ou um pouco menos mal, da complexidade dos objetos. (Ardoino, 1998d, p. 4)}

Ou seja, a

\begin{abstract}
[...] análise multirreferencial das situações das práticas dos fenômenos e dos fatos educativos se propõe explicitamente uma leitura plural de tais objetos, sob diferentes ângulos e em função de sistemas de referências distintos, os quais não podem reduzir-se uns aos outros. Muito mais que uma posição metodológica, trata-se de uma decisão epistemológica. (Ardoino, 1995a, p. 7)
\end{abstract}

Essa proposta de trabalho é elaborada num momento muito específico da educação francesa. Resgatando esse momento, Ardoino destaca:

\begin{abstract}
[...] nos anos 60 a situação da educação pública da França coloca questões de reificação, pois o aparelho educativo, um aparelho ideológico de estado para falar na linguagem de Althusser, faz que não haja mais elasticidade, não haja mais flexibilidade. Note bem, trinta e cinco anos depois o atual ministro da educação definiu o sistema educativo francês como um "mamute", que tem que emagrecer. Isto quer dizer que aí há uma forma de monstro pré-histórico, e isso quer dizer também que não houve muito progresso [durante todos esses anos]. Na época, 1965, isso já era visível e a complexidade emergia [...] no prolongamento de inovações cibernéticas, tecnológicas. Eu acho que são esses os fatores que vão nos conduzir [...] ao reconhecimento do plural. (Ardoino, 1998d, p. 2)
\end{abstract}

Quanto ao domínio científico daquele momento, ele avalia que existia e ainda existe
[...] uma idéia de pureza, da unidade, que encontra a idéia de homogeneidade. Então a multirreferencialidade é antes 
de tudo o reconhecimento do valor do plural [da pluralidade]. Quer dizer que esse plural vale pelo menos tanto quanto a unidade. Eu creio que isso já era verdade em 1965 ao nível das práticas, mas é tanto verdade também hoje, em 1998, e provavelmente porque se vê melhor o movimento de globalização que busca incansavelmente esta homogeneização. (Ardoino, 1998d, p. 2)

Temos, com base nessa posição de Ardoino, uma nova perspectiva para a compreensão dos fenômenos educativos: a da pluralidade e da heterogeneidade.

Como apontei em outro lugar (Martins, 1999), nosso sistema educacional - apesar das novas experiências e iniciativas - ainda aborda o processo educacional como aquele que deve oferecer um conjunto de experiências que assegure uma espécie de unidade, tendo em vista a "formação integral do educando".

Essa forma de abordar o processo, no entanto, traz implícita a noção de identidade, o que nos remete para a mesmice, para o igual - o que revela uma repetição do mesmo. Repetição que se distende sob duas perspectivas: a primeira diz respeito ao cumprimento das expectativas que professores e estudantes estruturam entre si (Aquino, 1996); a segunda refere-se ao próprio processo de aprendizagem, cujo desdobramento se revela nas "eternas repetições do conteúdo aprendido", que são realizadas pelos alunos durante sua vida escolar. Tais perspectivas, no entanto, modificam-se na medida em que considerarmos os espaços educativos em sua complexidade. A introdução dessa noção no âmbito educacional redimensiona-o, trazendo novas perspectivas para a pesquisa dos fenômenos que ali se estabelecem. É o que veremos a seguir.

\section{A noção de complexidade}

Como assinalei anteriormente, a noção de multirreferencialidade está estreitamente relacionada com a noção de complexidade. Ardoino toma essa noção no sentido que Edgar Morin lhe confere, ou seja:

Designamos algo que, não podendo realmente explicar, vamos chamar de "complexo". Por isso que existe um pensamento complexo, este não será um pensamento capaz de abrir todas as portas [...] mas um pensamento onde estará sempre presente a dificuldade. (Morin, 1996a, p. 274)

O termo complexidade traz em seu cerne confusão, incerteza e desordem. Para Morin, ele expressa "nossa confusão, nossa incapacidade para definir de maneira simples, para nomear de maneira clara, para pôr ordem em nossas idéias" (Morin, 1996b, p. 21). Conforme suas palavras, o pensamento complexo é visto como uma

\begin{abstract}
[...] viagem em busca de um modo de pensamento capaz de respeitar a multidimensionalidade, ${ }^{1}$ a riqueza, o mistério do real, e de saber que as determinações - cerebral, cultural, social, histórica - que se impõem a todo o pensamento co-determinam sempre o objeto de conhecimento. É isso que eu designo por pensamento complexo. (Morin apud Petraglia, 1995, p. 46)
\end{abstract}

Tal posição é claramente distinta da perspectiva epistemológica do conhecimento científico tradicional (cartesiano, positivo etc.), pois este último "foi concebido durante muito tempo, e ainda é freqüentemente, como tendo por missão dissipar a aparente complexidade dos fenômenos, com o intuito de revelar a ordem simples a que obedecem" (Morin, 1996b, p. 21).

A necessidade do pensamento complexo se impõe, portanto, quando o pensamento simplificador encontra seus limites, suas insuficiências, suas carências. No entanto, cabe ressaltar que a complexidade não elimina a simplicidade.

[...] A complexidade aparece ali onde o pensamento simplificador falha, mas integra em si mesma tudo aquilo que põe ordem, claridade, distinção, precisão no conhecimento. Enquanto o pensamento simplificador desintegra a complexidade do real, o pensamento complexo integra o mais possível os modos simplificadores de pensar, mas re-

${ }^{1}$ Observo que Ardoino não utiliza o termo muldimensionalidade, mas sim multirreferencialidade. 
cusa as consequiências mutilantes, reducionistas, unidimensionalizantes e finalmente ocultadoras de uma simplificação... (Morin, 1996b, p. 22)

Cabe ressaltar que, para Morin, o paradigma da complexidade não "produz" nem determina a inteligibilidade: "ele pode incitar a estratégia/inteligência do sujeito pesquisador a considerar a complexidade da questão estudada" (Morin, s.d., p. 334). Ou seja, para Morin, assim como para Ardoino (1998c), a complexidade não está no objeto, mas no olhar de que o pesquisador se utiliza para estudar seu objeto, na maneira como ele aborda os fenômenos.

A educação é entendida, no âmbito da abordagem multirreferencial, "como uma função global, que atravessa o conjunto dos campos das ciências do homem e da sociedade, interessando tanto ao psicólogo como ao psicólogo social, ao economista, ao sociólogo, ao filósofo ou ao historiador etc." (Ardoino, 1995a, p. 7). À medida que os fenômenos educativos são apreendidos enquanto complexidade, torna-se necessário uma abordagem que atente para essas várias perspectivas, reconhecendo suas recorrências e contradições, de tal forma que elas não se reduzam umas às outras.

Entretanto, uma abordagem tradicional - aquela cujos pressupostos vinculam-se ao racionalismo cartesiano ou ao positivismo - tem como perspectiva "recortar" o real, decompô-lo em elementos cada vez mais simples, cada vez mais fundamentais, cuja combinação resulta igualmente nas propriedades do conjunto, ou seja, o todo corresponde à soma de suas partes, e vice-versa.

Essa última postura pressupõe, para Ardoino, que os fenômenos educativos são susceptíveis de transparência, ou seja,

[...] algo mais que só aquilo que pode ser atravessado pelo olhar, abarcado, totalmente descrito, definido ou inspecionado segundo o sentido corrente, e incluir o que pode ser construído efetivamente, fisicamente, segundo a necessidade, mas ainda descontruído (decomposto) e reconstruído, idêntico, com todas suas propriedades, pelo espírito conhecedor. (Ardoino, 1995a, p. 8)
Para Ardoino, esse tipo de abordagem é possível quando se trata de fenômenos químicos, ou físicos, até mesmo matemáticos, mas "não há coincidência possível entre essa visão das coisas e o fenômeno vivo ou, mais especificamente ainda, humano e social. Nesse sentido, nenhuma redução é legítima" (Ardoino, 1995a, p. 8).

Atribuir a um objeto a característica de complexo significa, em princípio, que nós estamos nos defrontando com um problema lógico, e esse problema aparece quando a lógica dedutiva se mostra insuficiente para dar uma prova num sistema de pensamento, o que faz com que apareçam contradições insuperáveis.

Visto que o ser humano se caracteriza por uma multideterminação de fatores: sociais, econômicos, políticos, psíquicos etc., o que o localiza na ordem do complexo, as abordagens que se inspiraram no cartesianismo ou mesmo no positivismo, buscando na redução a compreensão para os fenômenos humanos, confrontam-se constantemente com os limites que essas posturas epistemológicas lhes impõem, acabando por produzir um conhecimento fragmentado e superficial.

Nesse sentido, tomando a educação em sua complexidade, bem como as ciências que fazem dela seu objeto, Ardoino, assinala:

Apesar das tentativas para "calcá-las” mais ou menos sobre o padrão das ciências exatas, já não podemos nos contentar atualmente com uma aproximação somente "positivista" no marco das ciências antropossociais, no seio das quais se situam, incontestavelmente, diferentes olhares que pretendem dar conta cientificamente dos fenômenos que interessam à educação e às práticas que põem esta em ação. (1995a, p. 8)

Com a noção de complexidade desenvolvida por Morin, Ardoino quer chamar a atenção para a necessidade de um "luto da ambição simplificadora", bem marcada pela ciência de inspiração cartesiana - dividir a dificuldade. "Reconhecer a complexidade como fundamental em um âmbito de conhecimento dado é então, por sua vez, postular o caráter 'molar', holístico 
da realidade estudada e a impossibilidade de sua redução por recorte, por decomposição em elementos mais simples" (Ardoino, 1995a, p. 8).

A perspectiva multirreferencial, à medida que postula que o conhecimento sobre os fenômenos educativos - considerando a complexidade destes últimos - deve ser construído através da conjugação e de aproximações de diversas disciplinas, inscreve-se num universo dialético e dialetizante, no qual o pensamento e o conseqüente conhecimento são concebidos em contínuo movimento, num constante ir e vir, o que possibilitará a criação e, com ela, a própria construção do conhecimento.

Reconhecer a necessidade de um olhar múltiplo para a compreensão dos fenômenos educativos implica um rompimento com o pensamento linear, unitário e reducionista característico do "paradigma de simplicidade" descrito anteriormente, e privilegiar o heterogêneo, como ponto de partida para a construção do conhecimento.

\section{Heterogeneidade e conhecimento}

Quando Morin desenvolve as hipóteses para estabelecer o paradigma de complexidade, ele assinala a necessidade de uma conjugação entre noções complementares, concorrentes e antagônicas: ele coloca como imprescindível a necessidade de estruturarmos o conhecimento científico a partir de vários pontos de vista, de tal forma que ele comporte suas diferenças e contradições.

Vamos encontrar esse mesmo princípio na proposta de Ardoino quanto à caracterização da abordagem multirreferencial, já que ele toma a pluralidade como ponto de partida para estabelecer os elementos que subsidiam tal abordagem: ela traz em si mesma a marca da heterogeneidade como o eixo principal na construção do conhecimento.

No âmbito dessa abordagem, a heterogeneidade deve ser entendida com base em duas perspectivas. A primeira está relacionada à conjugação de diversas disciplinas para o processo de elucidação dos fenô- menos humanos, o que vai circunscrever o modelo de inteligibilidade citado anteriormente.

Podemos dizer que o trabalho do pesquisador aproxima-se ao do bricoleur, como propõe Lapassade (1998). Essa idéia elaborada por Lapassade inspirouse nas considerações tecidas por Lévi-Strauss em Pensamento selvagem, quando discutiu as características do trabalho científico. Apesar de Lévi-Strauss não estar preocupado com a questão da complexidade dos fenômenos sociais, ele reconhece as dificuldades enfrentadas pelo pesquisador no desvelamento da realidade, em vista dos limites teóricos que ele enfrenta. Tal dificuldade leva o pesquisador a "negociar" com a realidade, buscando "pedaços de teorias heterogêneas", estabelecendo um conhecimento plural da realidade.

Ardoino (1998d) aponta, no entanto, que o problema em que a análise multirreferencial se coloca é utilizar várias linguagens para a compreensão dos fenômenos sem misturá-las, sem reduzi-las umas às outras; o conhecimento produzido por essa postura seria, portanto, um conhecimento "bricolado", "tecido" etc. Nesse sentido, Ardoino assinala que a compreensão da realidade se efetiva apelando "a sistemas de referências, a grades de leitura diferentes (psicológicas, psicossociais, sociológicas). [...] O trabalho de análise consiste menos em tentar homogeneizá-las, ao preço de uma redução inevitável, que em procurar articulálas, se não as conjugar" (Ardoino, 1995a, p. 7-8).

Tal forma de abordar os fenômenos traz implícita a idéia de complexidade desenvolvida por Morin. Conforme afirma esse autor:

A visão não complexa das ciências humanas, das ciências sociais, implica pensar que existe uma realidade econômica, por um lado, uma realidade psicológica, por outro, uma realidade demográfica, mais além etc. Acreditamos que essas categorias criadas pelas universidades são realidades, mas esquecemos que, no econômico, por exemplo, estão as necessidades e os desejos humanos. Por trás do dinheiro, existe todo um mundo de paixões. [...] A consciência da complexidade nos faz compreender que não po- 
deremos escapar jamais à incerteza e que jamais poderemos ter um saber total: "a totalidade é a não verdade". (Morin, 1996b, p. 100-101)

Ardoino articula-se, portanto, com o pensamento de Morin, com base na idéia de "complexidade" e da crença de que a barbárie dos tempos modernos, como a barbárie de todos os tempos, está no pensamento simplificante (Ardoino, 1995a, 1998c).

Cabe ressaltar que a análise multirreferencial não tem como pretensão "esgotar" seu objeto de estudo. Analisar, nesse contexto, não se define mais por sua capacidade de recortar, de decompor, de dividirreduzir em elementos mais simples, mas por suas propriedades de "compreensão", de "acompanhamento" dos fenômenos vivos e dinâmicos (Ardoino, 1995a, p. 9).

Além disso, a abordagem multirreferencial - à medida que não se caracteriza como um movimento de decomposição ou redução de seus objetos - aceita a opacidade própria dos fenômenos humanos (o que pressupõe, conseqüentemente, o reconhecimento de sua complexidade).

A outra perspectiva que gostaríamos de assinalar com relação ao papel da heterogeneidade na compreensão dos fenômenos humanos diz respeito à questão da relação entre sujeito e objeto. A ciência que se desenvolveu durante a modernidade tem como pressuposto a manutenção de um distanciamento entre os termos dessa relação, de tal forma que, se assim fosse, se asseguraria a objetividade e a neutralidade do conhecimento.

A abordagem multirreferencial retoma essa discussão assumindo que o conhecimento se realiza exatamente ali onde a ciência cartesiana e positivista não o reconhece: na relação mesma entre sujeito e objeto na relação intersubjetiva. Isto significa dizer que, no lugar de termos um objeto que se quer objetivo, nós iremos, na verdade, ter um objeto que é ao mesmo tempo sujeito (Ardoino, 1998d).

Ardoino, para explicitar melhor suas idéias, afirma que, no âmbito da pesquisa, os seres vivos, espe- cialmente os humanos, quando submetidos a quaisquer que sejam os determinismos (econômicos, sociais, culturais etc.) que condicionam e podem explicar seus modos de funcionamento, têm em si um poder de negação, de contra-estratégia, que lhes dá, ao menos em parte, a inteligência desses determinismos e uma certa capacidade de reagir e de adaptar-se, senão de transformá-los. Ardoino denomina essa capacidade de negatricidade, o que significa o reconhecimento de uma certa opacidade própria dos objetos que estão sob investigação. Ele define negatricidade como "a capacidade que o outro possui sempre de poder desmantelar com suas próprias contra-estratégias aquelas das quais se sente objeto" (Ardoino, Barbier \& Giust-Desprairies, 1998, p. 68). Isso quer dizer que o homem - tanto individual como coletivo - não é indiferente às produções de saber que lhe concernem e reagirá diante delas, interferirá constantemente com os dispositivos de análise e de investigação que lhe serão aplicados, perturbando seu funcionamento. ${ }^{2}$

Cabe ressaltar ainda que, do ponto de vista do pesquisador, Ardoino considera que, além de ele não dominar (no sentido de controle) seu objeto (em função da negatricidade que lhe é inerente), ele está implicado com ele/nele. A implicação é entendida aqui como

\section{[...] engajamento pessoal e coletivo do pesquisador em e por sua práxis científica, em função de sua história familiar e libidinal, de suas posições passadas e atual nas relações de produção e de classe, e de seu projeto sociopolítico em ato, de tal modo que o investimento que resulte inevitavel- mente de tudo isso seja parte integrante e dinâmica de toda atividade de conhecimento. (Barbier, 1985, p. 120)}

A idéia de implicação nos sugere que o processo de construção de conhecimento não se efetiva sob a

\footnotetext{
${ }^{2}$ Geertz (1978) explora esse tema no âmbito da antropolo-
} gia, apontando que o informante, no campo de pesquisa, elabora interpretações a respeito da realidade, e que o conhecimento que o antropólogo tem desta pode ser de "terceira mão". 
égide exclusiva de uma determinada racionalidade. Pelo contrário, o conhecer se estabelece com base em vários outros planos: das motivações mais profundas do pesquisador, de seus desejos (inconscientes?), de suas projeções pessoais, das suas identificações, de sua trajetória pessoal etc. Nesse sentido, podemos dizer que a relação entre sujeito e objeto propicia tanto o desvelamento do objeto como o desvelamento do sujeito.

Com a idéia de implicação assume-se que o conhecimento produzido no âmbito da abordagem multirreferencial é da ordem da intersubjetividade, o que significa reconhecer que a produção de conhecimento implica um processo de "negociação" entre as múltiplas referências que compõem o conjunto das representações de cada indivíduo envolvido no processo, ou seja, o conhecimento se produz a partir da heterogeneidade implícita nas relações que se estabelecem no campo da pesquisa.

Em outro lugar (Martins, 1995), tive a oportunidade de assinalar as vicissitudes inerentes à relação entre sujeito e objeto. Neste trabalho aponto para a necessidade de reconhecermos a imprevisibilidade que essa relação traz em si mesma, já que tanto o "outro", que foi tomado como objeto, como o pesquisador, estiveram submetidos a uma situação de "alteração", vindo a se influenciar mutuamente.

Tal situação, principalmente no que tange ao papel do pesquisador, tornou possível a emergência de alguns questionamentos de ordem pessoal que lhe possibilitaram redimensionar seu próprio projeto de pesquisa, levando-o ao reconhecimento de suas implicações ao longo da pesquisa.

As situações experienciadas no campo foram tão intensas - do ponto de vista psicológico e sociológico - que não foi possível manter a "clássica" relação entre sujeito e objeto (aquela prevista nos livros e manuais), levando o pesquisador a estabelecer uma relação sincrética com os seus "informantes".

O trabalho - a dissertação em si - foi-se dando à medida que foram se esclarecendo as implicações inerentes às relações que se estabeleceram durante o tra- balho de campo - o que podemos chamar de "perlaboração". ${ }^{3}$

Quero dizer com isso que a relação entre sujeito e objeto, entendida como um encontro intersubjetivo, requer o reconhecimento de dimensões que não estão relacionadas nem com os aspectos teóricos nem com os aspectos metodológicos que utilizamos quando da realização de nossas pesquisas. Tais dimensões estão circunscritas pela ordem do psíquico, do desejo, da vontade, o que implica o reconhecimento de afetos nem sempre "dizíveis" em nosso cotidiano acadêmico, mas que emergem durante a construção do conhecimento.

Muitas vezes as informações provenientes desse tipo de experiência são registradas em nossas anotações, em nossos cadernos de campo, e "lapidados" e "re-elaborados" pelo prisma da razão. ${ }^{4}$

Numa perspectiva psicológica, podemos dizer que a heterogeneidade intrínseca na relação entre sujeito e objeto caracteriza-se como processo de alteração, já que ela é circunscrita por um jogo de influências mútuas. A interação (alteração) desencadeia “jogos próprios das vontades, dos desejos, da angústia, das manifestações de uma vida inconsciente, de um funcionamento imaginário..." (Ardoino, 1995b, p. 19) que suscitam tantas estratégias, resistências, ambivalências, opacidades: expressões de uma negatricidade que permanecem ininteligíveis para um aparato racional. Tal situação, em função de sua complexidade, geralmente nos leva para os caminhos das incertezas e do inacabamento, condições impensáveis na ótica de uma epistemologia tradicional - cartesiana, positivista.

3 "Processo pelo qual a análise integra uma interpretação e supera as resistências que suscita. Tratar-se-ia de uma espécie de trabalho psíquico que permite ao indivíduo aceitar certos elementos recalcados e libertar-se da influência dos mecanismos repetitivos" (Laplanche \& Pontalis, 1967, p. 429).

${ }^{4}$ Sobre essa questão ver Borba (1997), especialmente o capítulo intitulado Jornal de pesquisa. 
A abordagem multirreferencial, enfim, nos abre a possibilidade de traçar um novo caminho no processo de elucidação dos fenômenos sociais, rompendo com a posição epistemológica desenvolvida ao longo da modernidade. ${ }^{5}$ Podemos dizer que esse rompimento restaura o espaço de sentido de cada participante da relação e nos permite pensar esse espaço restaurado como circunscrevendo o discurso de um sujeito falante - tanto para aquele que se diz pesquisador como para aquele que é olhado como objeto - libertando o homem da sua condição de objeto.

A proposta de Ardoino, por sua vez, nos leva ao reconhecimento de uma heterogeneidade própria do campo das ciências humanas, visto que esta se caracteriza por uma coexistência temporal de várias perspectivas teóricas, várias abordagens, vários paradigmas. Diferentemente das ciências naturais, que registram um contínuo processo de sucessão de teorias (conforme Kuhn, 1978), nas ciências humanas as vemos em plena simultaneidade, sem que uma nova teoria (ou abordagem, ou paradigma) elimine a anterior pela via das "revoluções científicas" de que nos fala Kuhn. Trata-se de uma convivência na qual todas "valem" à sua maneira, em função de sua própria forma de conhecer. $\mathrm{O}$ fato de aproximarmos perspectivas teóricas marcadas pela heterogeneidade engendra um campo de tensão, a partir do qual podemos vislumbrar novas perspectivas epistemológicas para a compreensão dos fenômenos humanos.

Cabe lembrar que o paradigma "cartesiano" nos ensinou a pensar no mundo como um cosmos "mecânico", um "universo maquininha", com peças fixas e movimentos previsíveis, num tempo/espaço absoluto. Sua lógica de sustentação vem da física e da matemática, que prescrevem o conhecimento embasado em quantificações e medidas. Aqui, o conhecimento é tanto mais científico e racional quanto forem diferenciadas as identidades dos "sujeitos" e "objetos". A pes-

${ }^{5}$ Martins (1998) sugere-nos uma aproximação da abordagem multirreferencial com as propostas epistemológicas desenvolvidas por autores pós-modernos. quisa, nesse modelo, prima pela captura de um objeto que existe fora do sujeito. O cientista moderno, porque se vê separado do objeto, busca uma teoria e uma metodologia e, em vão, forja uma união que revele a "verdade objetiva". Compartimentalização, causalidade, linearidade, determinismo... estes são alguns dos princípios básicos que sustentam os conhecimentos aí construídos. E é nessa perspectiva que aprendemos a fazer ciência. ${ }^{6}$

Esse tipo de formação, que tem como princípio a máxima de São Tomé que é a de "ver para crer", tem reduzido nossa realidade, que é múltipla e complexa, em "pedacinhos", em "fragmentos". A perspectiva multirreferencial vem problematizar tal prática colocando em discussão as bases sobre as quais construímos nosso conhecimento, propondo sua ampliação e sua complexificação: para além daquilo que pode ser grupado e contado (no sentido de numerado), vai também nos interessar aquilo que é contado (pela voz que diz) pela memória e pela fluidez do cotidiano, o que escapa, o lapso, a história, a fotografia esquecida na gaveta, a incerteza, o improvável, o imponderável...

A perspectiva que aqui apresento vem tentar superar uma prática no campo da educação cuja tendência é a de legitimar a razão instrumental, isto é, implementar uma proposta que se pauta no desenvolvimento de uma práxis reflexiva, superando a lógica implementada por uma racionalidade exclusivamente técnica.

JOÃO BATISTA MARTINS, doutor em educação pela Universidade Federal de São Carlos (UFSCar), é professor no Departamento de Psicologia Social da Universidade Estadual de Londrina. Organizou as seguintes publicações: Temas em análise institucional e em construcionismo social (São Carlos: RiMa / Curitiba: Fundação Araucária, 2002, 174p.) e Na perspectiva de Vygotsky (São Paulo: Quebra Nozes / Londrina: CEFIL, 1999, 109p.).E-mail: jbmartin@sercomtel.com.br

${ }^{6}$ Para uma discussão mais detalhada, ver Japiassu (1975) e Schwartz (1992). 


\section{Referências bibliográficas}

AQUINO, J.G., (1996). Confrontos na sala de aula: uma leitura institucional da relação professor-aluno. São Paulo: Summus.

ARDOINO, J., (1998c). Abordagem multirreferencial: a epistemologia das ciências antropossociais. Palestra proferida na Faculdade de Psicologia da Pontifícia Universidade Católica do Rio Grande do Sul, 14 out.

(1998a). Análise institucional: gênese, atualidade e perspectivas. Palestra proferida na Faculdade de Psicologia da Universidade Federal do Rio Grande do Sul, 13 out.

, (1995b). Dialogue à plusiers voies: à propos du sujet.

In: ARDOINO, J. Le directeur et l'intelligence de l'organization: repéres et notes de lecture. Ivry: ANDESI, p. 18-20.

, (1998d). A formação do educador e a perspectiva multirreferencial. Minicurso ministrado na Universidade Federal de São Carlos, Departamento de Educação, Programa de PósGraduação em Educação, de 15 a 16 de outubro. Mimeo.

, (1995a). Multiréferentielle (analyse). In: ARDOINO,

J. Le directeur et l'intelligence de l'organization: repéres et notes de lecture. Ivry: ANDESI, p. 7-9.

(1998b). Nota a propósito das relações entre a abordagem multirreferencial e a análise institucional (história ou histórias). In: BARBOSA, J.G. (coord.). Multirreferencialidade nas ciências e na educação. São Carlos: Editora da UFSCar, p. 42-49.

ARDOINO, J., BARBIER, R., GIUST-DESPRAIRIES, F., (1998)

Entrevista com Cornelius Castoriadis. In: BARBOSA, J.G., (coord.). Multirreferencialidade nas ciências e na educação. São Carlos: Editora da UFSCar, p. 50-72.

BARBIER, R., (1985). A pesquisa-ação na instituição educativa. Rio de Janeiro: Jorge Zahar.

BARBOSA, J. G., (1998). Posfácio. In: BARBOSA, J.G. (coord.). Multirreferencialidade nas ciências e na educação. São Carlos: Editora da UFSCar, p. 200-204.

BORBA, S.C., (1997). Multirreferencialidade na formação do “professor-pesquisador”; da conformidade à complexidade. Maceió: Edição do autor.

CAPRA, F. (1982), O ponto de mutação. São Paulo: Cultrix.

GEERTZ, C., (1978). Interpretação das culturas. Rio de Janeiro: Jorge Zahar.
GONZÁLEZ REY, F., (1997). Epistemologia qualitativa y subjetividad. São Paulo: EDUC.

JAPIASSU, H., (1975). O mito da neutralidade científica. Rio de Janeiro: Imago.

KUHN, T.S., (1978). A estrutura das revoluções científicas. $2^{\mathrm{a}}$ ed. São Paulo: Perspectiva.

LAPASSADE, G., (1998). Da multirreferencialidade como "bricolagem”. In: BARBOSA, J.G. (coord.). Multirreferencialidade nas ciências e na educação. São Carlos: Editora da UFSCar, p. 24-41.

LAPLANCHE, J., PONTALIS, J.-B., (1967). Vocabulário de psicanálise. São Paulo: Martins Fontes.

MARTINS, J.B., (1995). Marolas antropológicas: identidades em mudança na Praia do Santinho. Dissertação de mestrado em Antropologia Social. Universidade Federal de Santa Catarina.

(1998). Multirreferencialidade e educação. In: BARBOSA, J.G. (org.). Reflexões em torno da abordagem multirreferencial. São Carlos: Editora da UFSCar, p. 21-34. (1999). A noção de identidade e o olhar multirreferencial: colocando algumas questões para a educação! PSI Revista de Psicologia Social e Institucional, Londrina, v. 1, n 2 , p. 169-188.

MORIN, E., (s.d.). Ciência com consciência. Lisboa: EuropaAmérica

(1996a). Epistemologia da complexidade. In: SCHNITMAN, D.F. (org.). Novos paradigmas, cultura e subjetividade. Porto Alegre: Artmed, p. 274-279.

(1996b). Introducción al pensamiento complejo. Barcelona: Gedisa.

PETRAGLIA, I.C., (1995). Edgar Morin: a educação e a complexidade do ser e do saber. Petrópolis: Vozes.

PRIGOGINE, I., (1996). O fim da ciência? In: SCHNITMAN, D.F. (org.). Novos paradigmas, cultura e subjetividade. Porto Alegre: Artmed, p. 25-44.

SCHWARTZ, J. (1992). O momento criativo: mito e alienação na ciência moderna. São Paulo: Best Seller/Círculo do Livro.

Recebido em abril de 2003

Aprovado em janeiro de 2004 
José Gondra e Inára Garcia

$A$ arte de endurecer "miolos moles e cérebros brandos": a racionalidade médico-higiênica e a construção social da infância

Pensar a infância implica trabalhar com a idéia de uma vida segmentada, construir marcos de começo e término das diferentes fases, num gradiente de idades evolutivo e linear. Assim, a tentativa de especificar essas etapas termina por repartir a vida de forma detalhada, além de unificar o que se encontra recoberto em cada uma das supostas idades da vida. Unificação que não é propriedade de um passado mais recuado, pois persiste na atualidade a crença em uma infância homogênea e cronologicamente repartida. Dessa forma, a cronologia da vida, problematizada nesse trabalho, considera tanto a base, a carga e o tempo de amadurecimento biológico dos sujeitos, como as variantes culturais e a história, que também definem, de forma decisiva, as possibilidades surpreendentes do ser humano.

Palavras-chave: educação; infância; higiene

The art of hardening "soft minds and tender brains": a medicalhygienic rationality and the social construction of childhood

A reflection on childhood implies working with the idea of a segmented life, establishing initial and final limits for the different phases, in an evolving linear age scale. Thus, the attempt to specify such stages ends by dividing life up into multiple segments, in addition to unifying what remains hidden in each of the supposed ages of life. Unification is not the property of a more distant past, as the belief in a homogeneously and chronologically divided childhood persists up until now. In this way, the chronology of life discussed in this article, considers not only the base, load and time of people's biological maturation, but also the cultural differences and the history that define, in a decisive way, the surprising possibilities of the human being.

Key-words: education; childhood; hygiene

João Batista Martins

Contribuições epistemológicas da abordagem multirreferencial para a compreensão dos fenômenos educacionais

Apresenta as contribuições da abordagem multirreferencial para a compreensão dos fenômenos educacionais enfatizando os aspectos epistemológicos que ela contempla. Nesse sentido discute-se o momento histórico em que a noção de multirreferencialidade é estruturada e, em seguida, alguns conceitos utilizados que recolocam algumas questões epistemológicas inerentes ao processo de conhecimento acerca dos fenômenos sociais e, mais especificamente, aqueles concernentes à educação.

Palavras-chave: multirreferencialidade; educação; epistemologia

Epistemological contributions of the multi-referential approach to the understanding of educational phenomena

Presents the contributions of the multireferential approach to the understanding of educational phenomena emphasising the epistemological aspects. To this end, we discuss the historical moment in which the notion of multi-referentiality is structured as well as some of the concepts used to re-situate the epistemological questions inherent to the knowledge building process on social phenomena and, more specifically, those related to education.

Key-words: multi-referentiality; education; epistemology
Martha Marandino

Transposição ou recontextualização? Sobre a produção de saberes na educação em museus de ciências A transformação do conhecimento científico com fins de ensino e divulgação se constitui como espaço-tempo de produção de novos saberes. Com base nesse pressuposto, esse trabalho estudou o processo de transposição didática/museográfica e de recontextualização nos espaços de museus de ciências, procurando entender os mecanismos de constituição do discurso expresso nas exposições que abordam temáticas biológicas. Para isso, tomou-se por base referenciais teóricos advindos principalmente do campo da educação e da museologia que pudessem auxiliar na compreensão das especificidades que os museus impõem a esse processo de produção. Esse texto discute particularmente o processo de construção do referencial teórico utilizado na pesquisa, já que de uma escolha fundamentada no conceito de transposição didática/ museográfica, optou-se - com base nas críticas e nos limites do uso desse conceito - por assumir como principal suporte teórico o conceito de recontextualização. Com base nessa discussão foi intenção levantar limites e possibilidades do uso do conceito de transposição didática e analisar os desafios de trabalhar com o conceito de recontextualização para o estudo dos processos educativos nos espaços de museus de ciências.

Palavras-chave: transposição didática; recontextualização; transposição museográfica; educação em museus

Transposition or recontextualisation? On the production of knowledge in education in science museums The transformation of scientific knowledge for teaching or public communication purposes, constitutes a 